\title{
Review of the concept "digital literacy" and its implications on the study of the gender digital divide
}

\section{Working paper}

Milagros Sáinz (msainzi@uoc.edu)

Researcher at the IN3

Cecilia Castaño (ceciliacastano@hotmail.com)

Researcher at the IN3

Margarita Artal

Researcher at the IN3

Working Paper Series WP08-001

Research Group: Gènere i TIC

Coordination: Cecilia Castaño Collado

Submissed in: April 2008

Accepted in: April 2008

Published in: April 2008

\section{$\bullet$ UOC}

\section{IN3 Internet

www.uoc.edu 
Internet Interdisciplinary Institute (IN3)

http://www.uoc.edu/in3

Parc Mediterrani de la Tecnologia

Av. Canal Olímpic, s/n.

08860 Castelldefels

Barcelona (Espanya)

Tel. 936735000

Universitat Oberta de Catalunya (UOC)

http://www.uoc.edu/

Av. Tibidabo, 39-43

08035 Barcelona

Espanya

Tel. 932532300 


\section{Table of Contents}

Abstract

Introduction to the concept of digital literacy

1. Evolution of the concept digital literacy: from e-skills to digital fluency

2. The new look: digital or technological fluency

3. The importance of digital literacy in the study of the gender digital divide 


\title{
Review of the concept "digital literacy" and its implications on the study of the gender digital divide
}

\author{
Milagros Sáinz (msainzi@uoc.edu) \\ Researcher at the IN3 \\ Cecilia Castaño (ceciliacastano@hotmail.com) \\ Researcher at the IN3 \\ Margarita Artal \\ Researcher at the IN3
}

\begin{abstract}
The concept of digital literacy has evolved in different ways over the years in terms of the theoretical approach used to investigate its implications in the study of the gender digital divide in different real-life contexts. The main aim of this paper is to use an interdisciplinary approach to analyze some of the theoretical and empirical gaps in the study of the gender digital divide. We review some of the empirical studies on the subject and propose future research lines in order to fill some of the research gaps with regard to the implications of digital literacy in the analysis of the gender digital divide.
\end{abstract}

\section{Keywords}

Gender, digital divide, skills, digital literacy and digital fluency.

\section{Recommended citation:}

SÁINZ, M; CASTAÑO, C.; ARTAL, M. (2008). Review of the concept "digital literacy" and its implications on the study of the gender digital divide [working paper online]. UOC. (Working Paper Series; WP08-001). [Visited in: $\mathrm{dd} / \mathrm{mm} / \mathrm{yyyy}$ ].

<http://www.uoc.edu/in3/dt/eng/sainz castano artal.pdf> 


\section{Introduction to the concept of digital literacy}

The literature in this field has traditionally established a difference between the first and the second digital divide. The first digital divide is more related to access to technology, while the second digital divide is in line with different types of technology use and the degree of competence in technology (Atewell, 2001; Hargittai, 2002 and 2005; Korupp and Szydlik, 2005; van Dijk and Hacker, 2003).

The concept digital literacy is used as an extension and explanation of the second digital divide and it has been found an effective tool to describe and measure the type of skills in which different groups of people vary as a function of certain structural and contextual variables (for example, gender, race, socioeconomic level, income, place of origin). In this sense, Hargittai (2002) refers to the differences in people's online skills as the second digital divide. This author carried out an empirical study in order to overcome shortcomings in the literature when studying the digital divide in terms of "haves" and "haves not" concerning Internet access. More specifically, she stresses the need of bridging the gap in the literature between mere structural measures of access (first digital divide) and what people actually do online (second digital divide).

On the other hand, Dimaggio and Hargittai (2001) considered five dimensions of the digital divide: technical means (software, hardware, connectivity quality); autonomy of use (location of access, freedom to use the medium for one's preferred activities); use patterns (types of uses of the Internet); social support networks and skills (abilities to use the medium effectively).

Van Dijk (1999) distinguished four different kinds of barriers to access and the type of access they restrict:

- No possession of computers and network connections (material access)

- Lack of significant usage opportunities (usage access)

- Absence of elementary digital experience due to lack of interest, computer anxiety and unattractiveness of the new technology (mental access).

- Lack of digital skills as a result of insufficient user friendliness and inadequate education or social support (skills access).

This author defends that access problems relating to digital technology gradually shift from the first two kinds of access (structural barriers) to the last two kinds, which are factors within the second digital divide.

Nevertheless, there is a great dissemination of literature about what the digital divide entails: whether the use and access to computers or whether the use and access to the Internet. Even though there is a research line based on analyzing the use of computers and of the Internet independently, we should acknowledge that they are linked together. Both concepts have also evolved simultaneously in an attempt to adapt to the demands of the different contexts and to the consequent social needs. These concepts have appeared in the context of the new Information Society under different approaches: sociological, educational and psychological, which directly affect the factors, indicators or tendencies used to explain the impact of computer and Internet skills on our society.

At the same time, experience with technology seems to be a good predictor of technology expertise (Hargittai, 2005). Although some authors have observed that owning a computer at home predicts 
the use of sophisticated technologies (Morahan-Martin and Schumacher, 2007), it is worth mentioning and recognizing the fact that owning a computer at home does not involve being computer or Internet literate. The mere access to Internet does not entail a proper understanding by users of the information on the website (Hargittai, 2005).

Van Dijk and Hacker (2003) argue that public opinion and public policy are mainly preoccupied with the material access to computers and take for granted other barriers because they are not considered an important problem to be solved. These authors also admit the existence of lack of digital skills on the part of people living in advanced European nations (such as the Netherlands, a country that is supposed to be high-technology advanced).

In this paper, we will deal with the implications of digital literacy in the study of the gender digital divide, using an interdisciplinary approach. More specifically, we will use the perspective of social psychology, sociology, economy and education with the main goal of reviewing some of the theoretical and empirical gaps in the literature on these issues, together with a proposal of some future lines of research.

\section{Evolution of the concept digital literacy: from e-skills to digital fluency}

Paul Gilster (1997) initially coined the concept digital literacy as an attempt to define the replacement of TV, telephones and newspapers by new technologies and to refer to the ability of people to adapt to the web. Nonetheless, and as Jewitt (2006) suggests, the concept literacy has been fragmented into different types of literacy (visual, emotional, intellectual and digital) in an endeavor to adapt to the continuous new demands of new technologies.

In this sense, the concept digital literacy has evolved through the years and has been used to explain different aspects related to technological skills, such as Internet, on-line, electronic or computer skills. As suggested by Fulton (1997), the definition of technological literacy is a combination of information skills and literacy, communication skills and literacy and the skills necessary to function in a technological environment.

This concept has gradually acquired more relevance because having the skills to properly use and take advantage of computers and the Internet are important requirements to obtain admission to different educational programs and also to gain access to the labor market (Brynin, 2006; Korupp and Szydlik, 2005; van Dijk and Hacker, 2003). In this regard, computer literacy seems to be positively related to social activity and school performance, math and language skills, success in finding a job and hourly wages (Korupp and Szydlik, 2005).

Computer and Internet skills are currently important components of human capital (Hargittai and Shafer, 2006) and predict technology expertise (Morahan-Martin and Shumacher, 2007). At the same time, computer usage may partly account for the narrowing of the job-skills gender gap (Green, Felstead and Gallie, 2000) because it may give rise to women having high qualifications and experience in technology-related skills.

González and Zarco (2004), for instance, carried out empirical research in Spain with a sample of 438 students enrolled in different university courses and degree programs. The main purpose of this research was to examine gender similarities and differences in attitudes towards several of the requirements necessary to gain access to the labor market. Participants were asked to express their opinion about the use of computers and other new technologies, among other requirements for gaining access to the labor market. These authors found that female participants held more 
negative attitudes than their male counterparts toward the technological requirements needed to access the labor market.

On the other hand, van Dijk (1999) conceives digital skills not only as the abilities of operating computers and network connections, but also as the abilities to search, select, process and apply information from different sources. As Bunz, Curry and Vroon (2007) conclude, we get into skills that can be acquired with a low level of digital literacy because they are based on factors such as computer anxiety, low self-efficacy, computer training, age or gender.

Eshet-Alkalai (2004) specifically proposes a conceptual framework of digital literacy through the integration of five types of literacy that may help us to understand the different types of skills contained within the concept 'digital literacy'. This author defines digital literacy in terms of a growing variety of technical, cognitive and sociological skills, necessary to perform tasks and solve problems in digital environments (Aviran, Guirion and Esthet-Alkalai, 2006).

Digital literacy encompasses the following forms of literacy: photo visual, reproduction, information, branching and socio-emotional literacy. Nevertheless, it is worth mentioning that in early stages this author (Esthet, 2002) did not consider the socio-emotional dimension of digital literacy.

Photo visual literacy refers to "visual memory and intuitive-associative thinking, which help users to decode and understand visual messages easily and fluently". As photo visual communication plays a very important role in the process of learning, and due to the massive existence of sophisticated multimedia products integrating text, sound and motion in a synchronic way, the author recognizes the relevance of synchronic learning. This type of learning is based on synchronized stimulation of the learner by means of multimedia and requires a degree of synchronic literacy.

This author also describes reproduction literacy as "the ability to create a meaningful, authentic, and creative work of interpretation, by integrating existing independent pieces of information". On the other hand, he defines branching or hypermedia literacy as "a good sense of multidimensional spatial orientation or the ability to avoid loosing orientation when surfing through hyperspace". This type of literacy seems to be highly related to the use of complex cognitive skills (such as good metaphorical thinking, the ability to create mental models, concept maps and other abstract representation of the network structure) and the ability of attaining a high degree of cognitive flexibility.

Information literacy "comprises those cognitive skills used to evaluate information in an educated and effective manner. This type of literacy works as a filter to identify and avoid erroneous, irrelevant, or biased information". Eshet (2002) found in his empirical study that adults showed a higher degree of information literacy than younger people did. Esthet-Alkalai (2004) criticizes the lack of studies that have focused on relevant cognitive and pedagogical aspects to measure information literacy and the high density of research that has concentrated on strategies and habits of searching information.

Lastly, this author identified socio-emotional literacy, which is the most complex type of digital literacy. "Those people who are socio-emotionally literate are willing to share data and knowledge with others, capable of information evaluation and abstract thinking and are able to collaboratively construct knowledge". According to this author, socio-emotional literate users are also capable of detecting and anticipating certain 'dangers', such as viruses, in order to 'survive' in cyberspace. 


\section{The new look: digital or technological fluency}

Some authors refer to digital literacy in terms of digital fluency. Jewitt (2006) claims that the static notion of literacy 'as the acquisition of a set of competences' should be replaced by a notion of literacy as a dynamic process through which students use and transform multimodal signs and design new meanings.

The concept digital literacy includes practices related to Information and Communication Technologies (ICTs) that are necessary for ones work life and, of course, for daily life. Digital literacy is a concept that includes abilities or skills and intellectual capacity for abstract thought referred to as the Information Society. Tucket (1989) conceives digital literacy as a basic condition for the correct use and comprehension of technological infrastructures and considers that digital literacy is based on the following three concepts:

- General knowledge about what computers are able to do

- Enough skills to use them as an efficient tool

- Self confidence with computers

The American Association of University Women Educational Foundation (AAUW, 2000), assumes the necessity of redefining the concept computer literacy in order to include relevant concepts, skills and problem-solving strategies. In this report, the concept digital literacy is substituted by the concept digital fluency and is applied to the academic field. Fluency goals entail change, adaptability, connection to personal goals and promotion of lifelong learning. Fluency with information technology requires three kinds of interdependent knowledge: skills, concepts and capabilities. Skills are necessary for job preparedness and productivity, and involve change. Concepts explain how and why information technology works. Capabilities include managing complex systems and testing solutions.

Bunz, Curry and Voon (2007) argue that the expression literacy is a static concept while the word fluency involves change. According to these authors, the concepts "literacy" or "competency" do not take into account the fact that existing skills can become obsolete due to changes in technology. However, they adopt the use of the concept "fluency", because with this concept they can account for a more comprehensive capability for adapting or applying past knowledge to untried (future) situations.

They also defend that computer-email-web (CEW) fluency is a digital factor that may be overcome not by focusing on skill development but, rather, on anxiety reduction. For this reason, they conclude by stating the necessity of developing a fluency index to predict a person's fluency in using an unknown technology based on the characteristics of the technology and the person.

Conversely, the savvy report (AAUW, 2000) strives to take into consideration this adaptive notion of digital fluency and uses this perspective to gather information about the degree of technology savvy the participants perceived themselves as having.

Taking into consideration the aforementioned aspects, we defend the notion that digital fluency comprises a complex variety of cognitive, digital and social skills activated in order to achieve digital-related goals and adapt to different technological media, their properties and to their continuous shifts and advancements. This conception recognizes the synergy between the individual and the technology and the adaptive capacity of the individual to manage and survive in a digital environment. A person who is technologically fluent is capable of using previous 
knowledge and technological experience to learn new strategies to adapt to possible changes in that technology. An example would be when someone changes the model or type of mobile phone and automatically tries to operate the new handset in the same way he/she was accustomed with the old one. However, in time the individual identifies those applications and features of the new handset that are similar and/or different from the old one and learns new ways of solving possible function problems in order to operate it properly.

We also stress the active role the person plays in the use of technologies in different contexts (for instance, a person who is computer literate and makes different use of computers at work than when enjoying his/her free time). Our approach also assumes that the concept literacy is not accurate enough to express the process of adaptation of the person to new technological advancements and changes and does not take into consideration the fact that someone can be completely illiterate with certain computer applications (such as hardware or software), despite being computer literate. The level of technology literacy and fluency attainment is not the same for a computer programmer than for someone who has never used computers or who is a normal user of computers.

The literature discusses the relationship between permanent training in the organizational context and the learning-based organization. In this regard, Daniels (1994) observed that few people are aware of the importance that information has for the generation of ideas and the development of business. Oxbrow (1998) considers that the concept of digital literacy is something more than the mere acquisition of computing learning skills, which are primarily based on information knowledge. Oxbrow (1998) adheres to the idea that those countries and societies ignoring the need of improving their citizens' level of digital literacy are not in a favorable position to compete efficiently in this New Information era. This kind of reflection leads us to the incomplete advancement of a society restricted by the education and information of its citizens. Women, elderly people or people with low incomes can be taken as examples of social groups who may be relegated from digital literacy because they may not be perceived as having reached equal levels of computer training and information. Empowering those excluded social groups, especially women, should be a basic labor for studies and analyses regarding the attaining of digital literacy.

\section{The importance of digital literacy in the study of the gender digital divide}

Despite the interest held by many authors in analyzing the subsequent implications of digital literacy, we have observed an absence of empirical studies examining this construct under a gender perspective.

Some authors (Eshet, 2002; Esthet-Arhitai, 2004; Poynton, 2005) have investigated digital or computer literacy using a developmental approach, but they have not considered the possibility of analyzing gender differences when trying to understand possible consequences of digital literacy in contexts other than schools. Most empirical research on the impact of digital literacy in different real-life situations has been conducted with children and adolescents in school contexts. Conversely, the literature acknowledges the important role that teachers and public policy actions play in fostering the technological skills of children and youngsters (Fulton, 1997).

Poynton (2005) recognizes the necessity of looking at computer literacy based on a developmental approach, from kindergarten to adulthood. The author considers the academic, social and psychological advantages of being computer literate. He also argues about the importance of integrating computer literacy skills in the curriculum at different educational levels (primary, secondary and higher education). In his study, he employs a developmental approach in order to 
review the existing current and past empirical studies that have attempted to analyze the impact of computer literacy in different contexts. However, he focuses specifically on educational contexts. From kindergarten to late adolescence, gender differences in computer literacy have been associated with different factors: computer access, scarce presence of computer games sensitive to gender differences, lack of role models, the way children learn to use computers and to interact with them, together with social expectations.

In line with Fulton (1997), necessary technology skills have changed over time and those changes affect the ways in which technology skills are taught and assessed. In Spain, Coll (2005) argues that the concept illiteracy is changing because of the need of integrating the learning of writing skills and ICTs in the school curriculum. This author insists on the need for a higher degree of digital literacy for improving people's capacity for text comprehension.

In this sense, Esthet (2002) carried out an empirical study where it was observed that the younger the participants were, the higher their ability to perform successfully those tasks that required branching literacy. At the same time, adults' photo-visual literacy (conceived as the ability to decode graphic user interfaces) was much lower than that of the younger participants.

Research on the positive effect of frequency of home and school computer use on academic performance is not consistent. On the one hand, Wenlinksy (1998) demonstrated that, after removing the effects of parental education, race, and family income, lower math scores were associated with lower frequency of home and school computer use. On the other hand, Attewell and Battle (1999) showed that having a home computer was associated with good performance in mathematics and reading.

Regarding the impact of digital skills in the labor market, we know that in the European context technological progress has modified qualification demands. Work conditions for non-qualified people have worsened, creating an important gap between the salaries of qualified and nonqualified workers. Technical and organizational changes have also altered wages and there is an interesting relationship between technological innovation, wages and qualifications. As some studies show (for instance, Webster, 1996), people who frequently use the ICTs receive higher remunerations and this, consequently, causes an increase in demand for people with more ICTrelated skills and abilities, which at the same time influences the development of more specific training plans oriented to update workers in terms of new improvements and advancements in the ICTs.

The increasing productivity of big companies and certain activity sectors has been based on the interrelationship among the digital technologies, the knowledge and qualification of their workforce and the strategy of the networked organization. These elements of the labor market are very important for understanding the way in which certain sectors of our society are excluded from technological advancements and the consequent increases in their salaries.

Stainley (2003) analyzed a group of psychosocial obstacles interfering with individual motivation to become engaged with new technologies and potentially benefit from these new technologies, which involves being computer literate. This author proved that the perception of irrelevance of computer technology to one's life, the lack of confidence in one's perceived technological skills or competences and a negative self-concept about who and what one may become in technology may also be an obstacle to one's motivation to become computer literate. In addition, the author argues that non-computer users would be more motivated if all the aforementioned barriers to computer literacy were addressed. 
Computer anxiety is acknowledged as the major factor related to computer literacy (Bunz, Curry and Vroon, 2007). Nevertheless, there are several other factors that directly or indirectly -through computer anxiety- have an influence on technological fluency: self-efficacy, computer training, learning styles, past computer related experiences, age and gender.

There is a large body of empirical studies that provide evidence that women show more anxiety and phobias related to technology and computers than men do (Brosnan, 1998a, King, Bong and Blandford, 2002; Rosen and Macguire, 1990). This factor seems to be crucial in explaining women's negative attitudes toward technology and low self-concept of their technology ability. In this sense, Brosnan (1998b) proved empirically the relationship between computer anxiety and computer performance, based on the approach of self-efficacy. This author observed that computer anxiety directly influenced the number of correct responses participants emitted, whereas selfefficacy determined how the task was attempted.

Poynton (2005) pays special attention to the link between computer anxiety and computer literacy and the role educators play in reducing their students' levels of anxiety at school. At the same time, computer anxiety discourages women from using technology (Campbell, 1990) and also from choosing technology-related fields (Dickhäuser and Stiensmeier-Pelster, 2002).

The analysis of self-perceived or self-assessed skills and competences in technology has been a key element in the study of gender differences in digital literacy and fluency. In general terms, these studies concur in finding that women show a lower self-perception of their technological abilities than men do (Eurydice, 2005; Hargittai and Shafer, 2006; Sáinz, 2006; Whitley, 1997; Zarrett and Malanchuk, 2005; Zarrett, Malanchuk, Davis-Kean and Eccles, 2006). Furthermore, research indicates that self-perceived digital skills are an effective predictive factor of actual skills (Hargittai, 2005; Hargittai and Shafer, 2006).

As Hargittai (2005) claims, the literature lacks empirical measures of people's actual skills and recognizes that many studies give much importance to the assessment of self-perceived skills. For instance, Bunz, Curry and Voon (2007) carried out an empirical study where they observed the absence of gender differences in actual computer-email-web (CEW) fluency, nonetheless, women perceived lower CEW fluency than men. According to these authors, computer-email and web (CEW) fluency is an indicator of the gender digital divide that may be overcome not by focusing on skill development, but on anxiety reduction.

Official European surveys and reports (Eurydice, 2005; Eurostat, 2006; Sibis, 2005) try to measure electronic-skills (e-skills: computer and internet skills) based on an international approach. Eurydice (2005) focuses explicitly on measuring gender differences in participants' reported computer and Internet competence. Participants are required to assess their own skills regarding the following group of tasks: playing games, using a file, internet and mail use, file management, internet downloading, communication, spreadsheets and power point presentations and advanced applications.

Morahan-Martin and Schumacher (2007) observed that both computer and Internet skills were strong predictors of technological expertise. These authors proved that those participants who were skilled with computers and the Internet were more involved in cutting-edge technology. Nevertheless, they did not study to what extent computer and Internet skills were good predictors of technological expertise for males and females separately. 
Hargittai (2002) did not find significant gender differences in whether people are able to efficiently navigate the content of the web and how long they took to do it. This author (Hargittai, 2005) elaborated some years later a seven-point scale to analyze its predictive power for actual skills related to people's digital literacy, in combination with other scales. This new scale, containing selfreports of digital literacy, was found to be the best predictor of people's digital literacy.

\section{Discussion and future lines of research}

According to the review of literature on the conceptualization of digital literacy (different skills to deal with computers, network connections and information) and digital fluency (capability to adapt those skills to the different situations associated with technology), we assume that people have to be digitally literate in order to be able to achieve a proper degree of digital fluency. As illustrated in figure 1, and to sum up the aforementioned aspects, research on digital literacy and fluency is limited to the study of certain structural and psychosocial barriers and to some of their possible negative consequences in particular contexts, such as the school and the labor market.

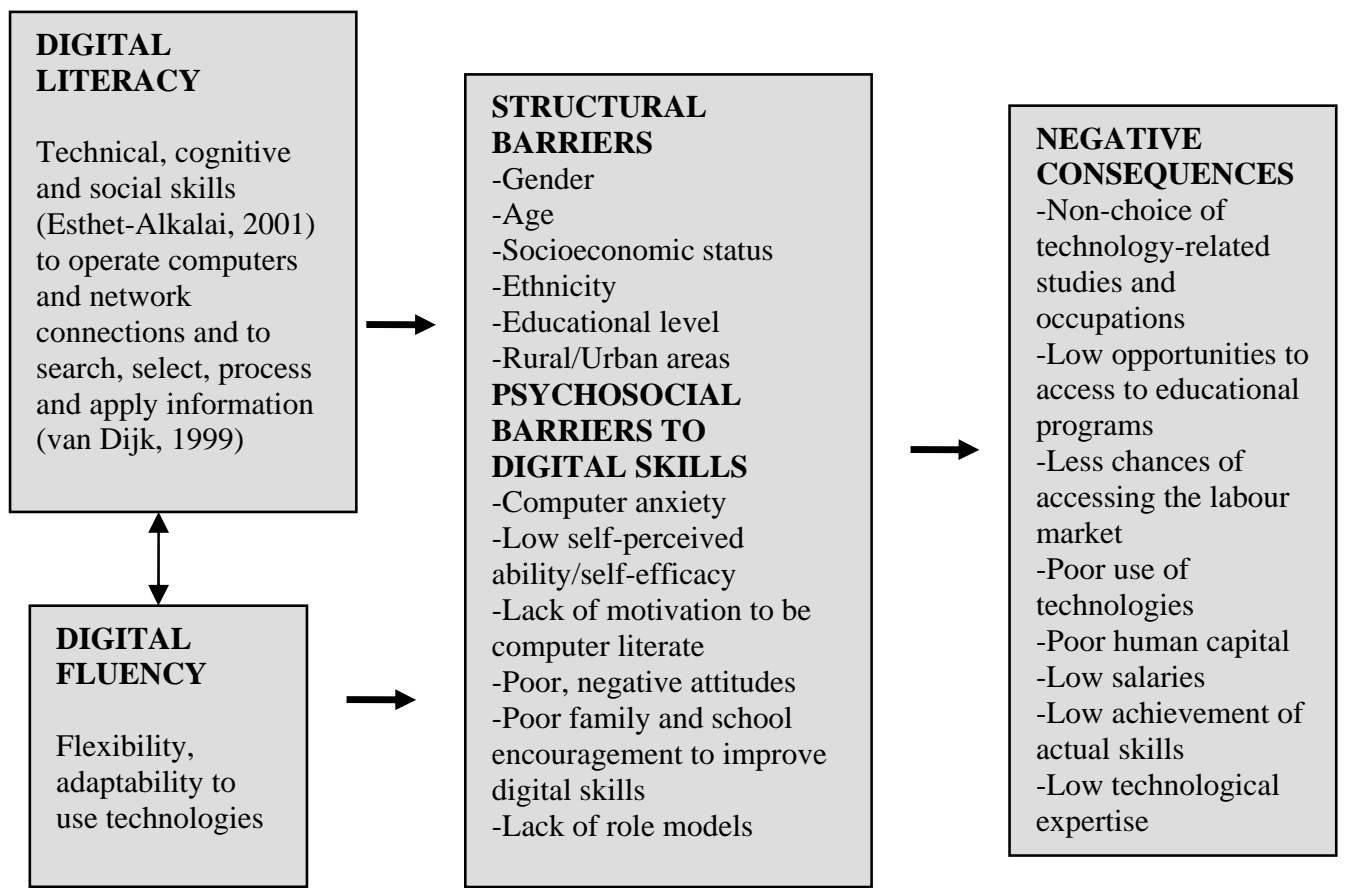

Figure 1. Representation of the conceptualization and barriers to digital literacy/fluency, together with their negative consequences

Computer anxiety and low self-perceived technological abilities are the most investigated psychosocial barriers to the attainment of digital literacy and fluency under a gender perspective. Nevertheless, attitudes towards technology, discouragement of socializers to improve digital skills, lack of motivation to be computer literate and absence of role models to improve digital skills are also important barriers to be further investigated.

Among the most important negative consequences of being digitally illiterate and non-fluent are poor use of technologies, the consequent lack of technological expertise, low opportunities to access to educational programs and to the labor market and low salaries (Korupp and Szydlik, 2005). 
Up to this point, we have considered digital literacy to be a very extensive concept that defines the mental structures enabling a wider acquisition of problem-solving strategies in the digital field. Regardless of the different conceptions of the concept, it is essential to understand that not attaining a satisfactory degree of digital literacy is associated with social and structural differences (the digital divide). Women are, among other social groups, threatened by this digital divide, which justifies realizing research studies that analyze this phenomenon using the gender perspective.

The problem behind the study and measure of digital literacy is that the conception of digital literacy or fluency is subject to the context in which the research is carried out and also to the various improvements and advancements in digital products and services. We cannot take for granted all these aspects and, therefore, prospect research should work to formulate and employ a unique global concept of digital or technological literacy that encompasses the most complete aspects of what being digitally literate or fluent means and accounts for.

Despite efforts to define the expression 'digital literacy', there is an absence of empirical research that analyzes the real impact of different structural and contextual factors on the acquisition of digital literacy. As many authors state (Bunz, Curry and Voon, 2007), it is necessary to create an index of considerable dimensions to measure actual computer and Internet skills. Future lines of research should try to analyze whether men are more technologically/digitally fluent than women are and whether the expected gender differences are more salient in any one context than in others.

Computer fluency and gender equity cannot be evaluated as a function of the number of women who send e-mails, use the Internet, or make PowerPoint presentations. Gender equity means using technology proactively, being able to interpret the information that technology makes available, understanding design concepts, and being a lifelong learner of technology. These abilities can be applied to a whole range of subjects and careers because they are not exclusive to the field of computer science or engineering (AAUW, 2000).

The American Association of University Women Educational Foundation (AAUW, 2000) argues that students must be trained to be literate citizens in a culture increasingly dependent on computers. Students, especially females, who predominate in clerical and service occupations, must be educated to move beyond word processing and presentation software to solve real-life problems with technology. Empowering women and other non-traditional users (for instance, immigrants, elderly people or people with a low educational level) to master different technological tools will contribute to bridge the digital gap in the academic and occupational contexts.

On the other hand, positive attitudes towards computers are good predictors of the election of IT and technology-related careers (Sáinz, 2006; Zarrett and Malanchuk, 2005; Zarrett, Malanchuk, Davis-Kean and Eccles, 2006) and help to explain the low representation of women in technologyrelated fields. In this sense, it will be of great interest to learn more about the way parents' perception of their own technological skills and their own attainment of computer fluency influence how they encourage their children to use technologies and pursue technology-related studies.

Congruently with Van Dijk and Hacker (2003), it would be necessary to perform longitudinal studies in order to analyze the hypothesized rise of a usage divide in terms of gender and of other structural variables. Van Dijk and Hacker (2003) recognize that the fundamental task of future society will be to prevent structural inequalities in the skill and usage of ICTs from becoming more acute. According to these authors, learning digital skills will be a strategic objective for educational institutions at all levels. They suggest that digital skills not only mean the ability to operate 
hardware and software (instrumental skills), but also the ability to search, select, process and apply information (informational skills) from digital sources and to strategically use them to improve one's position in society (strategic skills).

Moreover, there is a gap in the research on gender and online skill, as well as a conspicuous absence of empirical work relating self-perception of skill to actual skill (Hargittai and Shafer, 2006). It is also essential to study digital literacy/fluency in new skills as opposed to in already acquired ones.

As Stanley (2003) argues, it would be helpful to investigate whether computer literacy actually helps the underemployed increase their social and economic capital and gain access to the employment ladder. Korupp (2001) observed that income levels are positively influenced by the use of computers at work. For this reason, it would be necessary to investigate whether organizational retributive policy systems take into consideration people's digital skills.

In line with Attewell (2001), it would be useful to have a more complete picture of the skills that separate computer virtuosi from ordinary computer users in the workplace, as a guide to training youths (and adults) in ways that will make them most employable.

As the impact of home and school computers on academic performance is not sufficiently clear, it would be of great interest to further analyze the association between digital fluency and academic performance for boys and girls separately. At the same time, it would be quite interesting to examine to what extent teachers' perceptions of their own computer fluency have an influence on how they transmit gender roles about computers to their students and how they encourage boys and girls to make use of technologies and to enroll in technology-related studies.

In this sense, the study of the way female teachers reproduce the stereotyped image of women lacking in computer skills, will be also worthy of analysis and could contribute to further knowledge about the way female students are discouraged from choosing technology-related studies. This will also be crucial in order to formulate consequent intervention measures aimed at promoting women's participation in technology-related areas.

Finally, we would like to emphasize that the labor market has modified its qualifications demands, which are related to the workforce's technological skills. In this sense, acquiring these abilities or not, may clearly create a divide among retributions, labor prestige and professional development.

\section{References}

American Association of University Women (AAUW) Educational Foundation (2000). Tech-savvy. Educating girls in the new computer age. Retrieved April 21, 2007 from http://www.aauw.org/member_center/publications/TechSavvy/TechSavvy.pdf

Attewell, P. (2001). Comment: the first and the second digital divides. Sociology of Education, 74, 3, pp. 252-259.

Attewell, P. and Battle, J. (1999). Home computers and school performance. The Information Society, 15, pp. 1-10.

Aviram, A., Gurion, B. and Esthet-Alkalai (2006). Towards a theory of digital literacy: Three scenarios for the next steps. European Journal of Open, Distance and E-Learning. Retrieved April 2, 2007 from http://www.eurodl.org/materials/contrib/2006/Aharon_Aviram.htm 
Bawden, D. (2005). Revisión de los conceptos de alfabetización informacional y alfabetización digital.[Review of concepts on informational and digital literacy] Anales de documentación, 5, pp. 361-408.

Brosnan, M. J. (1998a). The impact of psychological gender, gender-related perceptions, significant others, and the introducer of technology upon computer anxiety in students. Journal of Educational Computing Research, 18, 63-78.

Brosnan, M.J. (1998b). The impact of computer anxiety and self-efficacy upon performance. Journal of Computer Assisted Learning, 14, pp. 223-234.

Brynin, M. (2006). Gender equity through computerisation. European Sociological Review, 22, 2, pp. 111-123.

Bunz, U., Curry, C. and Voon, W. (2007). Perceived versus actual computer-email-web fluency. Computers in human behavior, 23, pp. 2321-2344.

Campbell, N. (1990). High school students. Computer attitudes and attributions: gender and ethnic differences. Journal of adolescent research, 5, pp. 485-499.

Coll, C. (2005). Lectura y alfabetismo en la sociedad de la información. [Reading and illiteracy in the Information Society] UOC papers, 1, pp. 4-11.

Daniels, NC. (1994). Information technology, the management challenge. Addison Wesley: Reading MA.

Dickhäuser, O. and Stiensmeier-Pelster, J. (2002). Erlernte Hilflosigkeit am Computer? Geschlectsunterschiede in computerspezifischen Attributionen. Self-helplessness towards computers. Gender differences in attributions about computers. Psychologie in Erziehung und Unterricht, 49, 44-55.

Dimaggio, P. and Hargittai, E. (2001). From the digital divide to digital inequality: Studying Internet use as penetration increases. Princeton University Center for Arts and Cultural Policy Studies, Working Paper Series number 15.

Eshet, Y. (2002). Digital literacy: A new terminology framework and its application to the design of meaningful technology-based learning environments. In Proceedings of World Conference on Educational Multimedia, Hypermedia and Telecommunications 2002 (pp. 493-498). Chesapeake, VA: AACE.

Eshet-Alkalai, Y. (2004). Digital literacy: A conceptual framework for survival skills in the digital era. Journal of Educational Multimedia and Hypermedia, 13, 1, 93-106.

Eurostat. (2006). How skilled are Europeans in using computers and the Internet? Statistics in focus. Retrieved March 24, 2007 from http://epp.eurostat.ec.europa.eu/cache/ITY_OFFPUB/KSNP-06-017/EN/KS-NP-06-017-EN.PDF.

Eurydice. (2005). How boys and girls in Europe are finding their way with information and communication technology. Retrieved July 11, 2007 from http://www.eurydice.org/ressources/eurydice/pdf/0_integral/069EN.pdf

Fulton, K. (1997). Learning in a digital age: Insights into the issues. A publication of the Milken Exchange on Information Technology: Milken Family Foundation.

González, J. M. and Zarco, V. (2004). Semejanzas y diferencias de género en las actitudes hacia las demandas del mercado laboral. [Gender similarities and differences in attitudes toward the requirements of the labor market] Revista de Psicología Social, 19, 3, 231-253.

Green, F., Felstead, A. and Galie, D. (2000). Computers are even more important than you thought: An analysis of the changing skill-intensity of jobs. London School of Economics, Centre For Economic Performance, Discussion Paper 439.

Hargittai, E. (2002). Second-level digital divide: Differences in people's online skills. First Monday, 1-20. Available at: http://www.firstmonday.org/issues/issue7_4/hargittai/ [Retrieved: March 12, 2007].

Hargittai, E. (2005). Survey measures of web-oriented digital literacy. Social Science Computer Review, 23, 3, 371-379. 
Hargittai, E. and Shafer, S. (2006). Differences in actual and perceived online skills: the role of gender. Social Science Quarterly, 87, 2, 432-448.

Huyer, S. (2007). Cyberella in the classroom? Gender, education and technology. In Hafkin,N.J. and Huyer, S. Cinderella or Cyberella? Empowering women in the knowledge society. Bloomfield, C: Kunarian Press.

Jewitt, C. (2006). Technology, literacy and learning. A multimodal approach. New Jersey: Routledge.

King, J., Bong, B. and Blandford, S. (2002). An investigation of computer anxiety by gender and grade. Computers in Human Behavior, 18, 69-84.

Korupp, S.E. (2001). Employment relations and new technologies: Is Information Technology creating a digital divide on the German labour market? Working Paper. Erfurt University.

Korupp, S.E. and Szydlik, M. (2005). Causes and trends of the digital divide. European Sociological Review, 21, 4, pp. 409-422.

Morahan-Martin, J. and Shumacher, P. (2007). Attitudinal and experiential predictors of technological expertise. Computers in human behavior, 23, 2230-2239.

Oxbrow, N. (1998). Information Literacy. The final key to an information society. Electronic Library 16, 6, pp. 359-60.

Poynton, T. A. (2005). Computer literacy across the lifespan: a review with implications for educators. Computers in human behavior, 21, pp. 861-872.

Rosen, L.D. and Macguire, P. (1990). Myths and realities of computerphobia: a meta-analysis. Anxiety Research, 3, 157-191.

Sáinz, M. (2006). Aspectos psicosociales de las diferencias de género en actitudes hacia las nuevas tecnologías en adolescentes [Gender differences in attitudes toward new technologies: a psychosocial approach]. Injuve, in press.

SIBIS. (2005). E-Europe 2005 Key Figures for Benchmarking EU15. Retrieved April 10, 2007 from http://www.sibis-eu.org/files/WP4_D4-3-3_eEurope_EU15.pdf

Stanley, L.D. (2003). Beyond access: Psychosocial barriers to computer literacy. The Information Society, 19, pp. 407-416.

Tuckett, H. W. (1989). Computer literacy, information literacy and the role of the instruction librarian in coping with information illiteracy: Bibliographic instruction for the information age. Ann Arbor Ml: Pieran Press.

Webster, J. (1996). Shaping women's work. Gender, employment and Information Technology. London: Longman Sociology Series.

Van Dijk, J.V. 1999. The network society, social aspects of new media. Thousand Oaks, California: Sage.

Van Dijk, J.V. and Hacker, K. (2003). The digital divide as a complex and dynamic phenomenon. The Information Society, 19, pp. 315-326.

Wenglinsky, H. (1998). Does it compute? The relationship between educational technology and student achievement in Mathematics. Princeton: New Jersey: Policy Information Center of the Educational Testing Service.

Whitley, B. (1997). Gender differences in computer-related attitudes and behavior: a meta-analysis. Computers in human behavior, 13, pp. 1-22.

Zarrett, N.R. and Malanchuk, O. (2005). Who's computing? Gender and race differences in young adults' decisions to pursue an Information Technology career. New directions for child and adolescent development, 110, 65-84.

Zarrett, N.R., Malanchuk, O., Davis-Kean, P.E. and Eccles, J.S. (2006). Examining the gender gap in IT by race: young adults' decisions to pursue an IT career. In B. Aspray and J. MacGrath Cohooon (Eds.). Women and Information Technology: Research on the reasons for underrepresentation. Cambridge, Massachusetts: MIT Press. 
IN3 Internet

interdisciplinary

Institute

www.uoc.edu 